\title{
Extending Boundaries with Meta-Design and Cultures of Participation
}

\author{
Gerhard Fischer \\ Center for LifeLong Learning and Design (L3D) \\ University of Colorado \\ Boulder, CO 80309-0430 USA \\ gerhard@colorado.edu
}

\begin{abstract}
Human-computer interaction (HCI) has refocused many research efforts within computer science from a technology-centered view to a human-centered view. The developments so far, however, have seen humans mostly as users and consumers rather than astive contributors and designers.

This paper provides a conceptual framework based on meta-design and cultures of participation that democratize design and allows all stakeholders to evolve systems to fit their needs. It establishes a new extended discourse for HCI research in which information technologies are interwoven with human lives in all aspects of our existence (at home, working, teaching, learning, and being a citizen). Specific socio-technical environments instantiating the framework in different application domains are described, including: (1) environments for people with cognitive disabilities, (2) table-top computing systems for framing and solving complex urban planning problems, (3) modeling the buildings of the world in 3D, and (4) using Smart Grids to support energy sustainability. These examples show how metadesign and cultures of participation are design approaches that allow researchers and practitioners to extend boundaries by allowing all stakeholders to have more control over their artifacts and by providing opportunities to encourage and to support contributions by many people in personally meaningful activities.
\end{abstract}

\section{Keywords}

meta-design, cultures of participation, systemic problems, boundaries, distances, motivation, control, socio-technical environments

\section{ACM Classification Keywords}

H5.m. Information interfaces and presentation (e.g., HCI): Miscellaneous.

Permission to make digital or hard copies of all or part of this work for personal or classroom use is granted without fee provided that copies are not made or distributed for profit or commercial advantage and that copies bear this notice and the full citation on the first page. To copy otherwise, or republish, to post on servers or to redistribute to lists, requires prior specific permission and/or a fee.

NordiCHI 2010, October 16-20, 2010, Reykjavik, Iceland.

Copyright 2010 ACM ISBN: 978-1-60558

\section{INTRODUCTION}

In the last 20 years, research and development in humancomputer interaction (HCI) have made major contributions to support the productive and creative autonomy of individuals. Historically, however, these possibilities often have been of interest and accessible only to a small number of "high-tech scribes." Meta-design [21] is focused on the challenge of allowing users of software systems who are not primarily interested in software per se to modify, extend, evolve, and create systems that fit their needs.

What the personal computer has done for the individual, the Internet has done for groups and communities. The first decade of Internet use was dominated by broadcast models and contributed little to change the existing strong separation of designers and users imposed by existing media. Cultures of participation [19], supported by meta-design and the participatory web [31], represent an evolving framework to exploit computational media in support of collaboration and communication. Providing all citizens with the means to become co-creators of new ideas, knowledge, and products in personally meaningful activities presents one of the most exciting innovations and transformations of digital media, with profound implications to extend the boundaries of HCI research.

This paper identifies boundaries, defines conceptual frameworks (centered on meta-design and cultures of participation), and describes socio-technical environments [27] (in four different application domains) grounded in these frameworks. It discusses the implications of these research activities to extend the boundaries of HCI.

\section{BOUNDARIES}

A basic challenge insufficiently addressed by prior HCI research is that almost all of the significant problems of tomorrow will be systemic problems, which cannot be addressed by any one specialty. These problems require multi-disciplinary, multi-sector, and international collaborations, providing opportunities for knowledge workers to work in teams, communities, and organizations that encompass multiple ways of knowing and collaborating. Our research has focused specifically on complex, systemic design problems requiring cultural and epistemological pluralism to make all voices heard. As stakeholders who 
are separated by spatial, temporal, conceptual, and technological distances [18] are brought together, boundaries can be overcome based on these distances. These distances will be briefly characterized as representing boundaries that need to be understood, respected, and extended.

\section{Boundaries Based on Spatial Distance}

Bringing spatially distributed people together with the support of computer-mediated communication allows the prominent defining feature of a group of people interacting with each other to become shared concerns rather than a shared location. By allowing more people to be included, local knowledge can be exploited. These opportunities have been successfully employed by the open-source communities [34] as well as by social networks of people who have a shared concern (such as a family member with a disability [9]). Transcending the barrier of spatial distribution is of particular importance in locally sparse populations (e.g., as they exist among people with disabilities).

\section{Boundaries Based on Temporal Distance}

Design processes often take place over many years, with initial design followed by extended periods of evolution and redesign. In this sense, design artifacts are not designed once and for all, but instead gradually change over long periods of time. For example, within most computer networks, when a new device or technology emerges, the infrastructure is incrementally enhanced and updated rather than redesigned completely from scratch. To be able to do this requires that new designers "collaborate" with the original designers. Long-term collaboration is crucial for the success of evolutionary development. This is hampered when individual designers are not informed about how the decisions they make interact with decisions that were made in the past from designers whose voices have been lost.

\section{Boundaries Based on Conceptual Distances}

To analyze the contribution of voices from different communities, two types of communities can be differentiated: communities of practice (CoPs) and communities of interest (CoIs).

CoPs [46] consist of practitioners who work as a community in a certain domain undertaking similar work. Examples of CoPs are architects, urban planners, research groups, software developers, and end-users. CoPs gain their strength from shared knowledge and experience. However, they face the boundaries of domain-specific ontologies and tools, empowering the insiders but often creating barriers for outsiders and newcomers.

CoIs $[15,17,29]$ can be thought of as "communities-ofcommunities" brought together to solve a problem of common concern. Examples of CoIs are (1) a team of software designers, marketing specialists, psychologists, and programmers interested in software development; or (2) a group of citizens and experts interested in urban planning. Fundamental challenges facing CoIs are found in building a shared understanding, learning to communicate with and learning from others, and establishing a common ground.
These structures and skills often do not exist at the beginning but evolve incrementally and collaboratively. CoIs provide an example of the importance of combining voices from different communities.

\section{Boundaries Based on Technological Distances}

The preceding subsections emphasized computer-mediated collaboration among humans to reduce the gaps created by spatial, temporal, and conceptual distances. In HCI systems, substantial information is embedded in computational artifacts.

Unlike passive design materials, such as pen and paper, computational artifacts are able to interpret the work of designers and actively "talk back" to them [36]. However, barriers occur when the back talk is presented in a form that users cannot comprehend or when the back talk created by the design situation itself is insufficient, and additional mechanisms and information are needed. To increase the back talk of the situation, we have developed a series of critiquing systems [22] that monitor the actions of users as they work to achieve a common goal and inform the users of potential problems during this process.

\section{EXTENDING BOUNDARIES}

\section{Supporting Users as Active Contributors with Meta-Design}

In a world that is not predictable, improvisation, evolution, and innovation are more than a luxury - they are a necessity. The challenge of design is not a matter of avoiding the emergent, but rather of including it and making it an opportunity for more creative and more adequate solutions to problems.

Meta-design [21] explores objectives, techniques, and processes to enable users to act as designers and active contributors, allowing them to create new knowledge rather than restricting them to the consumption of existing knowledge. The need for meta-design is founded on the observation that design requires open systems that users can modify and evolve [24]. Because problems cannot be completely anticipated at design time when the system is developed, users at use time will encounter mismatches between their problems and the support that a system provides. These mismatches will lead to breakdowns [22] that serve as potential sources for new insights, new knowledge, and new understanding. Meta-design advocates a shift in focus from finished products or complete solutions to conditions for users to resolve mismatches and repair breakdowns when they are discovered during use.

Meta-design engages diverse contributors (individuals and communities) in designing and building their own tools and systems by democratizing design. Our future world will be substantially shaped by stakeholders who will design, build, and evolve their own devices - our goal is to inspire, shape, support, foster, and analyze these communities. Metadesign allows creative and unplanned opportunism by addressing one of the fundamental challenges of a knowledge 
society: to create socio-technical environments in which all participants in collaborative design processes can express themselves and engage in personally meaningful activities.

By allowing users to become co-designers, HCI needs to develop architectures, seeds, and features that provide all stakeholders with opportunities, tools, and social reward structures to extend and evolve systems to fit their needs.

In current design practices, teams of developers function as experts observing use and designing solutions to fit existing work practices, typically with input and involvement from users at one or more iterative stages. There is one "official" future toward which design efforts are oriented and around which design decisions are made. There is an intentional focus on the immediate needs of the current users; the end result must be a complete artifact, leading to rigid design decisions made at design time. These techniques yield closed systems based on decisions made at design time, and stakeholders are incapable of modifying and evolving the system when new and unanticipated requirements arise during use.

Design practices based on meta-design are focused on systems facing unpredictable future developments and changes. Participatory design includes users in the initial design process, but these participants can represent only the immediate users and immediate needs. Meta-design applies design techniques that enhance the further development of systems at use time. Design power is shifted towards the users, allowing them to ultimately act as both designers and consumers of the system and allowing the system to be shaped through real-time use. Table 1 summarizes the different role distributions.

\section{Transcending Consumer Cultures with} Cultures of Participation

The first decade of the World Wide Web predominantly enforced a clear separation between designers and consumers. New technological developments (such as participatory

\begin{tabular}{|l|l|l|}
\multicolumn{1}{|c}{$\begin{array}{c}\text { Design } \\
\text { Approach }\end{array}$} & \multicolumn{1}{c|}{ Design Time } & \multicolumn{1}{c|}{ Use Time } \\
\hline $\begin{array}{l}\text { professionally } \\
\text { dominated } \\
\text { design }\end{array}$ & users have no voice & $\begin{array}{l}\text { users have to live } \\
\text { with artifacts de- } \\
\text { signed by others }\end{array}$ \\
\hline $\begin{array}{l}\text { participatory } \\
\text { design }\end{array}$ & $\begin{array}{l}\text { users are active par- } \\
\text { ticipants; systems are } \\
\text { designed as complete } \\
\text { artifacts at design } \\
\text { time }\end{array}$ & $\begin{array}{l}\text { systems are designed } \\
\text { with users' input, but } \\
\text { they cannot be } \\
\text { evolved to serve } \\
\text { unforeseen needs }\end{array}$ \\
\hline meta-design & $\begin{array}{l}\text { users are active par- } \\
\text { ticipants; systems are } \\
\text { designed as seeds; } \\
\text { design is focused on } \\
\text { use } \text { and participation }\end{array}$ & $\begin{array}{l}\text { users can act as de- } \\
\text { signers and evolve } \\
\text { the artifact to fit new } \\
\text { needs }\end{array}$ \\
\hline
\end{tabular}

Table 1. The role of stakeholders in different design approaches
Web 2.0 architectures) have emerged to support social computing. These developments are the foundations for a fundamental shift from consumer cultures (specialized in producing finished goods) to cultures of participation (in which all people can participate actively in personally meaningful activities). Cultures of participation provide foundations for this fundamental transformation by exploring and supporting new approaches for the design, adoption, appropriation, adaptation, evolution, and sharing of artifacts by all participating stakeholders. These cultures are not dictated by technology alone; they are the result of incremental shifts in human behavior and social organizations [6].

A major objective of cultures of participation is to attract large number of contributors. A number of notable success models exist, including open source software, Wikipedia, Second Life, YouTube, and 3D Warehouse (our research is less focused on social networks that primarily serve communication purposes such as Twitter and Facebook). By breaking down the boundaries between producers and consumers, cultures of participation have created new opportunities and challenges.

\section{Breaking Down Strict Role Separations}

New concepts and models establishing middle ground between consumers and producers are emerging, including the following:

- Prosumers [44] are techno-sophisticated and comfortable with the technologies with which they grew up. They have little fear of modifying and evolving artifacts to their own requirements. They do not wait for someone else to anticipate their needs, and they can decide what is important for them. They participate in learning and discovery and engage in experimenting, exploring, building, tinkering, framing, solving, and reflecting.

- Professional amateurs [26] are innovative, committed, and networked amateurs working up to professional standards. They are new social hybrids, and their activities are not adequately captured by the traditional dichotomous definitions of work and leisure, professional and amateur, and consumption and production.

These new classes of contributors form the foundation for social production and mass collaboration [6] by relying on the following facts:

- A tiny percentage of a very large base is still a substantial number of people;

- Beyond the large quantitative numbers of contributors exists a great diversity of interests and passions among users;

- Although human beings often act for material rewards, they can also be motivated by social capital, reputation, connectedness, and the enjoyment derived from giving away things of value. 
Intrinsically motivated contributors can be found in the Long Tail [3], where people from around the world engage in topics and activities about which they feel passionate.

\section{Open Design Spaces and User-Generated Content}

Cultures of participation emphasize the "unfinished" and take into account that design problems have no stopping rule, need to remain open and fluid to accommodate ongoing change, and can be characterized as having "continuous beta" as a desirable attribute rather than a to-be-avoided detriment. Cultures of participation can move from guidelines, rules, and procedures to exceptions, negotiations, and work-arounds to complement and integrate existing accredited and expert knowledge with informal, practice-based, and situated knowledge $[42,47]$.

User-generated content includes: (a) creating artifacts with existing tools (e.g., writing a document with a word processor) or (b) changing the tools (e.g., writing macros to extend the word processor as a tool). In specific environments, such as open-source software, the content is subject to the additional requirement of being computationally interpretable. Different activities for content generation (e.g., adaptation, generalization, improvement requests, specialization, and tailoring [2]) need to be supported.

\section{Rich Ecologies of Participation}

Complex socio-technical environments cannot be understood as simple aggregations of the behavior of some nonexistent average user [37]. Stakeholders need to take on different tasks and responsibilities as they progress toward the demanding levels of participation. Most stakeholders will start as consumers, but only a small percentage will eventually become active contributors, curators, and metadesigners [33]. Creating innovative support mechanisms (e.g., learning environments, scaffolding, boundary objects) and social reward structures (e.g., intrinsic motivation, reputation economies, gift cultures) presents challenges for HCI research to reduce the funnel effect causing a limited migration toward more demanding roles [32].

\section{SOCIO-TECHNICAL ENVIRONMENTS EXTENDING BOUNDARIES IN SPECIFIC APPLICATION DOMAINS}

In the last decade, we have developed socio-technical environments to extend boundaries. In all of these application domains, socio-technical environments are needed because the deep and enduring changes of our ages are not technological in their core substance, but social and cultural. Changes in complex environments are not primarily determined by technology, but are the result of incremental shifts in human behavior and social organization. Sociotechnical environments are composed both of computers, networks, and software, and of people, processes, policies, laws, and institutions, thereby creating a complex web of socio-cultural concerns and requiring the co-design of social and technical systems. Meta-design and cultures of participation provide conceptual frameworks for the design of socio-technical environments because they give users design power to modify and evolve the systems according to their needs.

This section briefly describes four specific examples that extend boundaries with meta-design and cultures of participation:

- the Memory Aiding Prompting System (MAPS), which fosters communities and creates new support tools for people with cognitive abilities and their caregivers;

- the Envisionment and Discovery Collaboratory (EDC), which is a table-top computing environment supporting stakeholders from diverse backgrounds in face-to-face meetings;

- the three-dimensional (3D) modeling environment, which allows people from around the world to create and share 3D models; and

- Smart-Grid developments, which involve consumers actively as decision makers to support new approaches toward energy sustainability.

\section{Cognitive Lever (CLever): Helping People Help Themselves}

The CLever project has been a large-scale research project at the University of Colorado [9]. The project extended boundaries by complementing human minds through media and technologies. As an important development within CLever, the Memory Aiding Prompting System [8] is a meta-design environment in which caregivers can design task-support tools for people with limited memory and executive functions. Individuals with cognitive disabilities are often unable to live independently due to their inability to perform activities of daily living, such as cooking, housework, or shopping. By being provided with socio-technical environments to extend their abilities and thereby their independence, these individuals can lead lives less dependent on others. MAPS has explored meta-design by supporting mobile device customization, personalization, and configuration by caregivers and effective use by clients [10].

Meta-design is of critical importance for people with cognitive disabilities because they represent a "universe of one": a solution for one person will rarely work for another. The success of MAPS is based on the empirical findings that (a) unexpected islands of abilities exist (clients can have unexpected skills and abilities that can be leveraged to ensure a better possibility of task accomplishment); and (b) unexpected deficits of abilities exist. Accessing and addressing these variations in skills and needs, particularly with respect to creating task support, requires an intimate knowledge of the client that only caregivers can provide. Currently, a substantial portion of all assistive technology is abandoned, resulting in the very population that could most benefit from technology paying for expensive devices that end up in the back of closets after a short time. 


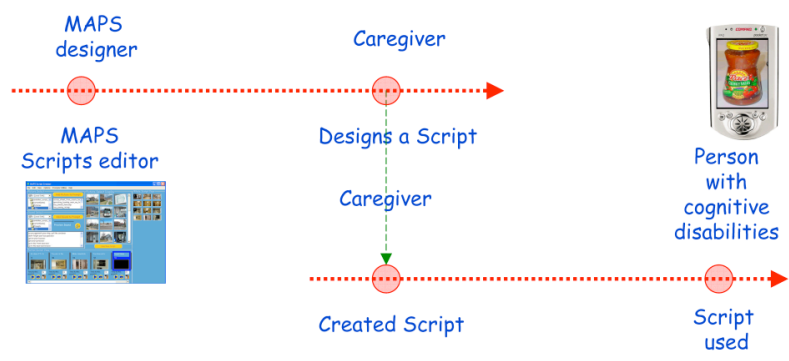

Figure 1 Meta-design in MAPS: Empowering caregivers to act as designers

A unique challenge of meta-design in the domain of cognitive disabilities is that the clients themselves cannot act as designers, but the caregivers must accept this role (see Figure 1). Caregivers, who have the most intimate knowledge of the client, need to be empowered to become the end-user designers. The scripts needed to effectively support users are specific for particular tasks, creating the requirement that the people who know about the clients and the tasks (i.e., the local caregivers rather than a technologist far removed from the action) must be able to develop scripts.

Caregivers generally have no specific professional technology training, nor are they interested in becoming computer programmers. Based on extensive end-user support, MAPS allows caregivers to design complex multimodal prompting sequences (including sound, pictures, and video to be assembled by using a film-strip-based scripting metaphor).

The design of MAPS involves three different groups of participants: assistive technology professionals and special education teachers, parents of clients, and professional caregivers. MAPS was tested with representatives of several different groups, resulting in the identification of the following requirements for meta-design: (a) discover and learn about the client's and caregiver's world and their interactions; (b) observe and analyze how tasks and learning of tasks were currently conducted; (c) understand and explicate the process of creating and updating scripts; (d) comprehend and analyze the process of using the scripts with a real task; and (e) gain an understanding of the role of meta-design in the dynamics of MAPS adoption and use.

By designing the MAPS environment to enable script redesign and reuse, caregivers were able to create an environment that matched the unique needs of individuals with cognitive disabilities. MAPS represents an example for extending boundaries by supporting meta-design, embedding new technologies into socio-technical environments, and helping people with cognitive disabilities and their caregivers have more interesting and more rewarding lives.

\section{Supporting Collaborative Design with the Envisionment and Discovery Collaboratory}

The Envisionment and Discovery Collaboratory (EDC) [4] is a long-term research platform that explores conceptual frameworks for extending boundaries in the context of framing and resolving complex urban planning by bringing together participants from various backgrounds in face-toface meetings. In this platform, the knowledge to understand, frame, and solve such problems does not already exist [16], but is constructed and evolves during the solution process - an ideal environment to study meta-design and cultures of participation.

The EDC represents a socio-technical environment that incorporates a number of innovative HCI technologies and approaches, including (a) table-top computing, which fosters and invites participation by maximizing the richness of communication among stakeholders in face-to-face interaction; (b) the integration of physical and computational components, which supports new interaction techniques [14]; and (c) an open architecture, which supports metadesign activities.

Figure 2 shows three different but integrated components of the EDC:

- the action space (bottom pane), in which stakeholders engage in participatory problem solving and decision making related to urban planning issues that are of concern to all participants;

- the reflection space (top left pane), in which task-relevant information is displayed for the design created in the action space;

- embedded visualizations using Google Earth (top right pane), in which the impact of new buildings are shown.

The vision of the EDC is to provide contextualized support for reflection-in-action [36] within collaborative design activities. In our research with the EDC during the last decade, we have extended the following boundaries:

- Transcending limited engagement with cultures of participation. Participants are more readily engaged if they perceive the design activities as personally meaningful by associating a purpose with their involvement $[7,35]$.

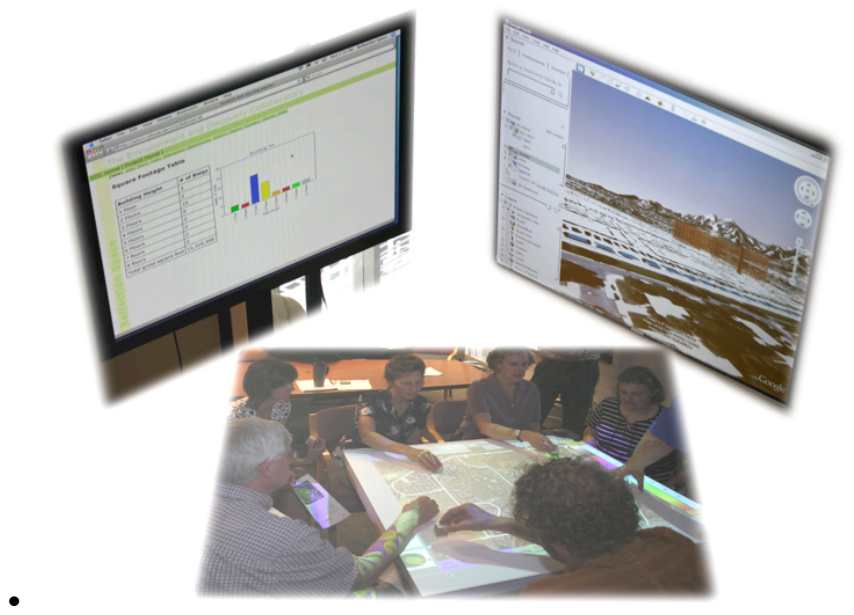

Figure 2. Different components of the EDC: action space, reflection space, and visualization support 
Participants must be able to naturally express what they want to say [28], and the interaction mechanisms offered must have a "low threshold" for easy participation and a "high ceiling" for expressing sophisticated ideas [38].

- Transcending group think by involving stakeholders with different interests and different knowledge. More creative solutions to problems can emerge from the collective interactions with the environment by heterogeneous communities (such as communities of interest [17], which are more diverse than communities of practice $[25,46])$. Boundary objects are needed [41] to establish common ground and establish shared understanding for communities of interest.

Obstacles to further investigate the above objectives rest with the difficulties of democratizing the design of the EDC [45] by providing more control to the participants. Currently, EDC participants have to customize the system at the source-code level to reflect the specific characteristics of the city and its urban planning problem. Support for end-user developments is important for the EDC, because each urban planning problem is unique: it has to take into consideration the geography, culture, and population of specific cities. In most cases, EDC developers (the metadesigners) do not have sufficient knowledge of the problem and the social context; they do not know which issues are of greatest concern to the city planners and citizens and which conflicts need to be resolved through the EDC system.

\section{Modeling the World in 3D: SketchUp, Building Maker, 3D Warehouse, and Google Earth}

Having the whole world modeled in $3 \mathrm{D}$ and allowing users to explore this virtual world on their computers is the objective behind Google's effort to integrate SketchUp, Building Maker, 3D Warehouse, and Google Earth. The amount of work and local knowledge needed to model billions of buildings is beyond the scope and capability of any locally operating development team. It requires the contributions of a large user base, and as such represents a unique, large-scale example for assessing the conceptual framework underlying meta-design and cultures of participation.

SketchUp and Building Maker are 3D-modeling environments (http://sketchup.google.com/). SketchUp allows users to develop sophisticated and highly creative models, but it requires a substantial learning effort. Building Maker is a tool for creating simpler models from aerial images with less effort. Powerful learning mechanisms for these systems are critical to allow everyone who wishes to contribute to learn how to do so.

The $3 D$ Warehouse is an information repository for the collection of models created by all users who are willing to share their models (see http://sketchup.google.com/3 dwarehouse/). It contains tens of thousands of models from different domains, including buildings, houses, bridges, and so forth, and it uses collections to organize models. In addition, the environment supports tagging, ratings, and reviews by the participating community. Interested users can utilize 3D Warehouse for creative collaborations by sharing, downloading, modifying, extending, and reusing existing models. Google Earth has the capability to show objects contained in 3D Warehouse. shows Downtown Denver, Colorado, in 3D as an example.

In an ongoing collaboration with our partners from the Google Boulder office in Colorado, we are extending boundaries by pursuing the following research issues.

- Allowing users to act as active contributors to 3D Warehouse requires extensive learning support to achieve sufficient mastery of the tools and environments provided.

- Assessing the effectiveness of different reward structures (recognition by the community and featuring the best models in 3D Warehouse and Google Earth) for motivating users to participate in the collaborative effort to model the whole world.

- Supporting richer ecologies of participation, including roles such as creators, raters, curators, power users, and local developers, while attending to the diversity and independence of participants.

\section{Smart Grids and Energy Sustainability}

Emerging changes in renewable and sustainable energy include rethinking how electricity is produced, transmitted, distributed, and consumed. The Smart-Grid vision [12] combines electrical and intelligence infrastructures. In March 2008, Boulder, Colorado, was selected to serve as the first Smart-Grid City in the United States. The vision and objective behind Smart-Grid Cities concept is focused on a number of infrastructure upgrades and customer offerings, including:

- transformation of the existing metering infrastructure to a robust, dynamic electric system and a communication network for two-way communication throughout the distribution grid;

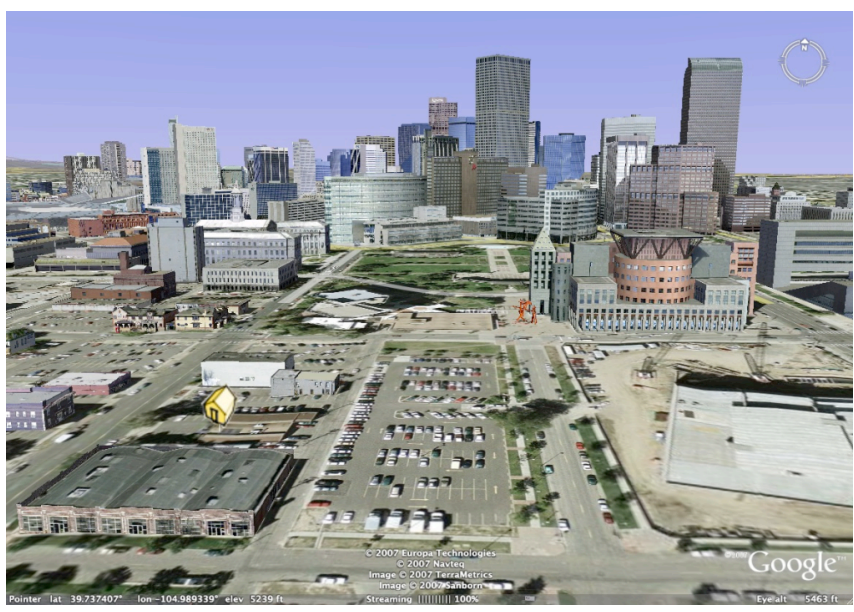

Figure 3. Downtown Denver, Colorado, in 3D 
- conversion of substations to "smart" substations capable of remote monitoring, near real-time data, and optimized performance; and

- installation of programmable in-home control devices (at the customer's invitation) and the necessary systems for more intelligent home energy use.

The Smart-Grid vision represents a challenging application domain for meta-design and cultures of participation. Our research [13] is grounded in the basic assumption that to harvest the benefits of Smart Grids, the underlying technologies are necessary but they are not sufficient. To take advantage of Smart Grids, humans must be engaged as active decision makers, and not only as passive consumers. The socio-technical environments must identify and offer the right balance between "automating" and "informating" $[30,48]$. Taking advantage of the potential of the new emerging technologies will require new mindsets that lead to changes in the way users (as individuals, communities, organizations, and governments) think and learn about energy sustainability.

\section{DISCUSSION AND REFLECTIONS}

A promising methodology to extend boundaries in $\mathrm{HCI}$ research is to exploit the synergistic efforts by applying and testing the conceptual frameworks (meta-design and cultures of participation) in the socio-technical environments discussed in the previous section and in return modifying and expanding the conceptual frameworks by the demands for specific applications. provides a summary how the four different application domains extend boundaries. The following subsections describe a number of themes that originated from these synergistic efforts.

Transcending the Unaided Individual Human Mind The primary HCI objective of the past to support and educate individual reflective practitioners [36] needs to be

\begin{tabular}{|c|c|}
\hline Application & Extending Boundaries \\
\hline CLever & $\begin{array}{l}\text { universal design; caregivers are em- } \\
\text { powered to be active developers }\end{array}$ \\
\hline $\mathrm{EDC}$ & $\begin{array}{l}\text { support for small groups in face-to-face } \\
\text { meetings with table-top computing, } \\
\text { boundary objects, visualizations, and } \\
\text { simulations; individual artifacts (urban } \\
\text { planning environments) are complex } \\
\text { and wicked problems }\end{array}$ \\
\hline 3D Modeling & $\begin{array}{l}\text { decentralized mass collaboration, rich } \\
\text { ecology of participation; the complexity } \\
\text { is primarily in the aggregate (hundred } \\
\text { thousands of models exist in the 3D } \\
\text { Warehouse) }\end{array}$ \\
\hline Smart Grids & $\begin{array}{l}\text { environments to support, inform, and } \\
\text { motivate users to act as active decision } \\
\text { makers in the use of energy }\end{array}$ \\
\hline
\end{tabular}

Table 2: Summary of how the different applications extend boundaries complemented by designing socio-technical environments focused on reflective communities. There is an urgent need for understanding, stimulating, fostering, and supporting creative co-production with meta-design and cultures of participation beyond support for solitary activity.

As cultures evolve, specialized knowledge becomes favored over generalized knowledge [39]. Taking advantage of the distances (spatial, temporal, conceptual, and technological) discussed earlier in this paper represents promising developments for making as many voices as possible heard, exploiting the symmetry of ignorance between different communities of practice with communities of interests [20], and creating shared understanding among stakeholders from different disciplines [40]. Specifically, the EDC is an attempt to extend boundaries by addressing these challenges.

\section{Understanding the Impact of Personally Meaningful Activities}

Actively contributing in cultures of participation, even when supported by powerful meta-design environments, requires a substantial amount of learning and engagement. All humans have a limited amount of time and attention, so they have to carefully choose the activities in which they decide to become active contributors. Socio-technical environments can fail in two directions:

- By forcing participants to act as designers when they prefer to be consumers; this is the case in personally irrelevant activities (depending on the individual, examples of such environments might be having to check one's own baggage at airports or check out one's own groceries at supermarkets);

- By limiting participants to consumer roles when they want to be active contributors and designers; this is the case in personally relevant and meaningful activities (examples of such activities for different individuals and communities are provided by the four application domains discussed in the previous section-providing more independence for a family member with a cognitive disability by using the MAPS system represents a personally meaningful problem for the caregiver).

\section{Motivation, Control, Ownership, Creativity, and Quality of Artifacts}

Meta-design and cultures of participation create a new understanding of motivation, creativity, control, ownership, and quality [6] - topics that have not been considered of great importance for HCI in the past, but which enter center stage in extending the boundaries for the next generation of HCI systems.

\section{Motivation}

Human beings are diversely motivated beings. We act not only for material gain, but also for psychological wellbeing, for social integration and connectedness, for social capital, for recognition, and for improving our standing in a reputation economy. The motivation for going the extra 
step to engage in active participation was articulated thus [35]: "The experience of having participated in a problem makes a difference to those who are affected by the solution. People are more likely to like a solution if they have been involved in its generation; even though it might not make sense otherwise." There is widespread evidence that people attach more value to things they create themselves (the so-called "Ikea effect" [5]). Meta-design relies on intrinsic motivation for participation; it offers a new platform for human connection by bringing together otherwise unconnected individuals and replacing common background or geographic proximity with a sense of well-defined and shared purpose. Motivation is critical in the framework and systems discussed in this paper because participation cannot be enforced, only encouraged, fostered, and supported (as indicated by the proverb: "one can lead a horse to water but one cannot make it drink"). Research in motivation transcends usability concerns (what people can and cannot do) by focusing on what people want to do [11].

\section{Control}

The importance of the distribution of control has been emphasized as important for architecture [1]: "I believe passionately in the idea that people should design buildings for themselves. In other words, not only that they should be involved in the buildings that are for them but that they should actually help design them." Meta-design and cultures of participation distribute control among all stakeholders in the design process and are based on the observation that shared control will lead to more innovation [45]: "Users that innovate can develop exactly what they want, rather than relying on manufacturers to act as their (often very imperfect) agents."

\section{Ownership}

Our experiences gathered in the context of the design, development, and assessment of our systems indicate that meta-design methodologies are less successful when users are brought into the process late (thereby denying them ownership) and when they are "misused" to fix problems and to address weaknesses of systems that the developers did not fix themselves. Meta-design works when users are part of the participatory design effort in establishing a meta-design framework, including support for intrinsic and extrinsic motivation, user toolkits for reducing the effort to make contributions, and the seeding of use communities in which individuals can share their contributions.

\section{Creativity}

Where do new ideas come from in meta-design environments and cultures of participation? Their creativity potential is grounded in user-driven innovations, taking advantage of breakdowns as sources for creativity, and exploiting the symmetry of ignorance [20]. To increase social creativity requires: (a) diversity (each participant should have some unique information or perspective), (b) independence (participants' opinions are not determined by the opinions of those around them) [43], (c) decentralization (participants are able to specialize and draw on local knowledge) [3], and (d) aggregation (mechanisms exist for turning individual contributions into collections). By focusing on open systems and on the unfinished, meta-design and cultures of participation create architectures and seeds that can be evolved on an ongoing basis.

\section{Quality of Artifacts}

Quality assurance in systems created by cultures of participation is often grounded in the following concern: "How are we to know that the content produced by widely dispersed and qualified individuals is not of substandard quality? " An interesting case study to reflect upon this concern was done in the context of Wikipedia. The journal Nature has compared the quality of articles found in the Encyclopedia Britannica with those in Wikipedia [23] and has come to the conclusion that Wikipedia comes close to Britannica in terms of the accuracy of its science entries.

\section{CONCLUSIONS}

Democratization of the development and evolution of personally meaningful socio-technical environments is more than letting users customize their applications; it represents a fundamental new challenge allowing and supporting the co-creation of situational applications. Empowering and motivating users to become active contributors and decision makers is a grand challenge problem for HCI research. In doing so, we should not ignore that boundaries are in many contexts important means for distinguishing communities and strengthening their identity. The challenge is not ignoring or eliminating boundaries, but respecting them and making them traversable as needed to explore new approaches and new frontiers.

\section{ACKNOWLEDGMENTS}

I thank the members of the Center for LifeLong Learning \& Design (L3D) at the University of Colorado, who have made major contributions to the ideas described in this paper. I specifically would like to thank: Elisa Giaccardi, who is the co-developer of our meta-design framework; Stefan Carmien, who created and evaluated the MAPS environment; Hal Eden, who is the major architect and developer of the EDC; John Bacus from Google Boulder, who provided unique insights into the design of the 3D modeling effort; and Holger Dick and Hal Eden, who are developing the Smart Grid environment.

The research was supported in part by (1) grants from the National Science Foundation, including: (a) IIS-0613638 "A Meta-Design Framework for Participative Software Systems," (b) IIS-0709304 “A New Generation Wiki for Supporting a Research Community in 'Creativity and IT'," and (c) IIS-0843720 "Increasing Participation and Sustaining a Research Community in 'Creativity and IT'”; (2) a Google research award "Motivating and Empowering Users to Become Active Contributors: Supporting the Learning of High-Functionality Environments"; and (3) a 
major grant "CLever: Cognitive Levers: Helping People Help Themselves" from the Coleman Institute for Cognitive Disabilities at the University of Colorado.

\section{REFERENCES}

1. Alexander, C. The state of the art in design methods. In N. Cross (Ed.), Developments in Design Methodology, John Wiley \& Sons, New York, 1984, 309-316.

2. Andersen, R. and Mørch, A. Mutual development: A case study in customer-initiated software product development. In V. Pipek, M.B. Rossen, B. deRuyter, and V. Wulf (Eds.), End-User Development, Springer, Heidelberg, 2009, 31-49.

3. Anderson, C. The Long Tail: Why the Future of Business Is Selling Less of More. Hyperion, New York, 2006.

4. Arias, E.G., Eden, H., Fischer, G., Gorman, A., and Scharff, E. Transcending the individual human mindCreating shared understanding through collaborative design. ACM Transactions on Computer HumanInteraction, 7, 1 (2000), 84-113.

5. Ariely, D. The Upside of Irrationality - the Unexpected Benefits of Defying Logic at Work and at Home..HarperCollins, New York, 2010.

6. Benkler, Y. The Wealth of Networks: How Social Production Transforms Markets and Freedom. Yale University Press, New Haven, CT, USA, 2006.

7. Brown, J.S., Duguid, P., and Haviland, S. Toward informed participation: six scenarios in search of democracy in the Information Age. The Aspen Institute Quarterly 6, 4 (1994), 49-73.

8. Carmien, S. Socio-Technical Environments Supporting Distributed Cognition for Persons with Cognitive Disabilities. Ph.D. dissertation, University of Colorado at Boulder. http://13d.cs.colorado.edu/ carmien/.

9. Carmien, S., Dawe, M., Fischer, G., Gorman, A., Kintsch, A., and Sullivan, J.F. Socio-technical environments supporting people with cognitive disabilities using public transportation. Transactions on HumanComputer Interaction (ToCHI) 12, 2 (2005), 233-262.

10. Carmien, S.P., and Fischer, G. Design, adoption, and assessment of a socio-technical environment supporting independence for persons with cognitive disabilities. In Proc. CHI 2008, ACM Press (2008), 597-607.

11. Csikszentmihalyi, M. Flow: The Psychology of Optimal Experience, HarperCollins Publishers, New York, 1990.

12. Department of Energy, Smart Grid. http://www.oe.energy.gov/smartgrid.htm.

13. Dick, H., Eden, H., and Fischer, G. Energy sustainability and Smart Grids: Fostering and supporting cultures of participation in the energy landscape of the future. (submitted for publication, 2010).
14. Eden, H. Getting in on the (inter)action: Exploring affordances for collaborative learning in a context of informed participation. In G. Stahl (Ed.), Proc. CSCL '2002 Conference, Boulder, Colorado (2002), 399-407.

15. Ehn, P. Manifesto for a digital bauhaus. Digital Creativity 9, 4 (1998), 207-216.

16. Engeström, Y. Expansive learning at work: Toward an activity theoretical reconceptualization. Journal of Education and Work 14, 1 (2001), 133-156.

17. Fischer, G. Communities of interest: Learning through the interaction of multiple knowledge systems, In Proc. IRIS'24, Ulvik, Norway (2001), 1-14.

18. Fischer, G. Social creativity: Turning barriers into opportunities for collaborative design. In F. deCindio and D. Schuler (Eds.), Proc. PDC'04, CPSR, University of Toronto, Canada (July 2004), 152-161.

19. Fischer, G. End-user development and meta-design: Foundations for cultures of participation. Journal of Organizational and End User Computing 22, 1 (2010), 52-82.

20. Fischer, G., Ehn, P., Engeström, Y., and Virkkunen, J. Symmetry of ignorance and informed participation. In Proc. PDC'02, Malmö University, Sweden (2002), 426-428.

21. Fischer, G., and Giaccardi, E. Meta-design: A framework for the future of end user development. In H. Lieberman, F. Paternò, and V. Wulf (Eds.), End User Development. Kluwer Academic Publishers, Dordrecht, The Netherlands, 2006, 427-457.

22. Fischer, G., Nakakoji, K., Ostwald, J., Stahl, G., and Sumner, T. Embedding critics in design environments. In M.T. Maybury and W. Wahlster (Eds.), Readings in Intelligent User Interfaces. Morgan Kaufmann, San Francisco, 1998, 537-559.

23. Giles, J. Internet encyclopaedias go head to head. $\mathrm{Na}$ ture 438 (2005), 900-901.

24. Henderson, A., and Kyng, M. There's no place like home: Continuing design in use. In J. Greenbaum and M. Kyng (Eds.), Design at Work: Cooperative Design of Computer Systems, Lawrence Erlbaum Associates, Inc., Hillsdale, NJ, USA, 1991, 219-240.

25. Janis, I. Victims of Groupthink, Houghton Mifflin, Boston, MA, USA, 1972.

26. Leadbeater, C., and Miller, P. The Pro-Am Revolution - How Enthusiasts Are Changing Our Economy and Society, 2008. http://www.demos.co.uk/files/proamrevolutionfinal.pdf

27. Mumford, E. A socio-technical approach to systems design. Requirements Engineering, 2000, 59-77.

28. Myers, B.A., Ko, A.J., and Burnett, M.M. Invited research overview: End-user programming. In Proc. Human Factors in Computing Systems, CHI'2006, Montreal (2006), 75-80. 
29. National Research Council. Beyond Productivity: Information Technology, Innovation, and Creativity, National Academy Press, Washington, DC, 2003.

30. Norman, D.A. Things That Make Us Smart AddisonWesley, Reading, MA, USA, 1993.

31. O'Reilly, T. What Is Web 2.0 - Design Patterns and Business Models for the Next Generation of Software. http:/www.oreillynet.com/pub/a/oreilly/tim/news/ 2005/09/30/what-is-web-20.html.

32. Porter, J. Designing for the Social Web. New Riders, Berkeley, CA, USA, 2008.

33. Preece, J., and Shneiderman, B. (2009) The reader-toleader framework: Motivating technology-mediated social participation. AIS Transactions on HumanComputer Interaction 1, 1 (2008), 13-32.

34. Raymond, E.S., and Young, B. The Cathedral and the Bazaar: Musings on Linux and Open Source by an Accidental Revolutionary. O'Reilly \& Associates, Sebastopol, CA, USA, 2001.

35. Rittel, H. Second-generation design methods. In N. Cross (Ed.), Developments in Design Methodology, John Wiley \& Sons, New York, 1984, 317-327.

36. Schön, D.A. The Reflective Practitioner: How Professionals Think in Action, Basic Books, New York, 1983.

37. Shirky, C. Here Comes Everybody: The Power of Organizing without Organization. Penguin Books, New York, 2008.

38. Shneiderman, B. Creativity support tools: Accelerating discovery and innovation. Communications of the ACM 50, 12 (2007), 20-32.
39. Simon, H. A. The Sciences of the Artificial, 3rd ed. The MIT Press, Cambridge, MA, USA, 1996..

40. Snow, C.P. The Two Cultures, Cambridge University Press, Cambridge, UK, 1993.

41. Star, S.L. The structure of ill-structured solutions: Boundary objects and heterogeneous distributed problem solving. In L. Gasser and M.N. Huhns (Eds.), Distributed Artificial Intelligence, Volume II, Morgan Kaufmann, San Mateo, CA, USA, 1989, 37-54.

42. Suchman, L.A. Plans and Situated Actions. Cambridge University Press, Cambridge, UK, 1987.

43. Surowiecki, J. The Wisdom of Crowds. Anchor Books, New York, 2005.

44. Tapscott, D., and Williams, A.D. Wikinomics: How Mass Collaboration Changes Everything, Portofolio, Penguin Group, New York, 2006.

45. von Hippel, E. Democratizing Innovation, MIT Press, Cambridge, MA, 2005.

46. Wenger, E. Communities of Practice - Learning, Meaning, and Identity. Cambridge University Press, Cambridge, UK, 1998.

47. Winograd, T., and Flores, F. Understanding Computers and Cognition: A New Foundation for Design Ablex Publishing Corporation, Norwood, NJ, USA, 1986.

48. Zuboff, S. In the Age of the Smart Machine, Basic Books, Inc., New York, 1988. 